\author{
Military Technical College \\ Kobry El-Kobbah, \\ Cairo, Egypt.
}

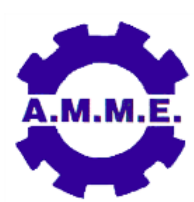

$17^{\text {th }}$ International Conference on Applied Mechanics and Mechanical Engineering.

\title{
SCORING MODELS FOR AUTOMOTIVE MULTISTAGE MECHANICAL TRANSMISSIONS USING PRINCIPAL COMPONENT ANALYSIS
}

\author{
A. O. Raslan*, W. M. Hussein* and Y. I. El-Shaer
}

\begin{abstract}
Sophisticated, accurate fault detection and diagnosis of monitoring processes can minimize downtime, increase safety of automotive transmission and gear systems, and reduce costs. To tackle this problem, transmission systems data was studied and analyzed to automatically characterize normal system behavior and anomaly detection and fault diagnosis methods based on multivariate latent techniques. Predictive health monitoring (PHM) systems are currently gaining in popularity due to their effectiveness in providing robust information about the system condition and reducing maintenance costs. However, PHM systems require reliable monitoring techniques, such as vibration, acoustic emission, and oil debris analysis. These techniques have shown the need to apply intelligent algorithms in order to benefit from the advantage of each technique in classifying faults and predicting the onset of failure. This paper presents a soft sensor technique namely Principal Component Analysis (PCA) for monitoring different gear faults using vibration analysis. Experiments were conducted on a multistage gearbox under five conditions, normal, external excitation at two positions, high temperature and high temperature with external excitation. The model is verified through additional experimental observations.
\end{abstract}

\section{KEYWORDS}

Mechanical transmission, condition based maintenance, vibration analysis, health monitoring system, Principal Component Analysis.

* Egyptian Armed Forces. 


\section{INTRODUCTION}

One of the main concerns of any automotive equipment is to ensure the health and safety of transmission gear system. The worst case in this circumstance is probably the loss of a mission but the more common interruption of gear functionality can result in compromised task objectives. Condition monitoring soft sensors hold information related to state-of-health $(\mathrm{SOH})$ of its subsystems. Each parameter has information which represents a time-variant property (i.e. a status or a measurement) to be checked. Moreover, the tremendous increase in data volume and its complexity directs the need for more efficient and scalable data processing system. As a consequence, there is a continuous improvement of transmission gear monitoring applications in order to quickly respond to changes in automotive missions.

Also, in some applications there is more demanding aspect such as saving man's life other than reliability [1]. Smith [2], has defined the causes of transmission vibration and its transmission path, including factors such as manufacturing error, design error and gear tooth deflection, which combine to introduce a transmission error (TE), which is the primary source of the vibration.

Over the past decade, vibration analysis proved to be a trustworthy diagnostic technique that can provide reliable information. However, in the last 10 years researchers devoted a much effort to support Condition Based Maintenance CBM actions using vibration information [3-13].

The work focused on the development of reliable features using a suitable signal processing techniques can be grouped in two groups; time domain vibration features including: statistical parameters, time synchronous averaging based methods, filter based methods, stochastic methods and other model based methods. The second group is the frequency domain and time frequency domain features including: first order; (FFT), correlation of spectrum, signal averaging, short time Fourier transform (STFT), continuous wavelet transform (CWT), discrete wavelet transform (DWT), discrete wavelet packet analysis (DWPA), time-averaged wavelet spectrum (TAWS) and time-frequency scale domain (TFS). Second order; power spectrum, Power cepstrum (logarithm of Power spectrum), cyclostationarity, spectrogram Wigner distribution and scalogram. Third order; Bicoherence spectrum, bilinearity and Wigner bi Spectra. Fourth order; Wigner tri Spectra [29].

The authors of this paper developed soft-sensor fusion algorithms to fuse vibration analysis information with other sensory data, such as acoustic emission and oil debris analysis to minimize false alarms that may occur in failure prediction [14-17]. Also, other researchers devoted efforts to build intelligent algorithms based on vibration features including Expert systems, ANN's, Genetic algorithm, and fuzzy logic [18 - 28]. Intelligent health monitoring systems incorporate Al algorithms, where Al can be defined as "the science of making machines do things that would require intelligence if done by humans" [33]. To develop an IHMS, the running system condition must be recognized and classified. Researchers have devoted considerable effort to the application of various different soft computing methods to develop IHMSs, and have shown that this can be achieved using methods such as neural networks, fuzzy logic and mathematical modelling based on parametric approaches. All of these methods 
can provide important tools in the field of intelligent systems which can learn, adapt, and make decisions concerning the system they are in charge of [33].

Artificial neural networks (ANNs) have been used with different HMS techniques such as vibration and acoustic monitoring. An ANN requires input data of the healthy and faulty conditions to be pre-processed, and then these features are used to model the system's behavior. Fenton et al [36] mentioned that there are two main basic network architectures: feed-forward and recurrent ANNs. Feed-forward ANNs do not have feedback between layers, and previous inputs are not remembered, whereas recurrent ANNs involve feedback between layers and previous inputs are remembered and can be used to reconstruct correlative memory. The two standard neural network architectures used in transmission diagnostics are the feed-forward back propagation network, and the Kohonen feature map which is also known as the self-organizing map (SOM) [37]. Fuzzy logic was developed by Zadeh in the 1960s to characterize types of knowledge that cannot be represented by classical Boolean algebra to cover approximate knowledge in describing the behavior of systems which are difficult to describe mathematically [33].

Currently, the authors of this paper is devoting their efforts in developing smart CBM systems that can use one analysis technique only such as vibration or acoustic emission analysis along with intelligent algorithms to predict the onset of failures; this is to reduce costs of different sensory requirements [30-32]. This paper builds on the author's previous work to develop an online wireless vibration analysis tool for testing automotive mechanical transmissions. The online operation of this system can lead to the wide spread of using such systems with other rotating machinery.

Parametric methods based on mathematical modelling is to fit measured time series waveform data to a parametric time series model, and then extract features based on this model [34]. Two models are currently in use: the auto regressive (AR) and autoregressive moving average (ARMA) models. The advantage of mathematical modeling based on parametric methods over the neural networks model-based method is its ability to deal with time series data directly without the need for a signal pre-processing step to extract useful features that can be modeled to represent the system [14]. However, they can only be used to model a time series signal such as a vibration signal, and cannot be applied to combined information from several techniques (vibration, AE and ODA) such as in the case of fuzzy logic.

In Addition, researchers have devoted considerable effort to the application of various different soft computing methods to develop heath monitoring systems HMSs for gear box transmission systems summarized in data mining techniques. These methods can provide important tools for the field of intelligent monitoring which can learn, adapt, and make decisions concerning the system they are in charge of TakehisaYairi et al. [45] evaluating a variety of dimensionality reduction algorithms and compare between them, without using the cross-validation.

Artificial neural networks ANNs in combination with other soft computing methods have been the most predominant to date [42, 43]. However, ANN techniques are characterized as black box approaches which model the relationship between different sensory data and a desired response without giving any information about the process. In addition, issues associated with collinearity and dimensionality needs to be 
specifically addressed in these techniques. Solving many of these limitations can be addressed through the use of multivariate statistical analysis, which is a data-driven modelling approach [43]. Iverson et al. [38, 39, 44] discuss several data driven software tools that successfully applied to space mission operations using data mining tool which searches for unusual data points, or outliers, in multivariate data sets in the spacecraft system data that may indicate malfunctioning system components. John MacGregor et al. [45] established the advantages applying of multivariate latent variable monitoring and fault diagnosis methods contrasted with other techniques as Independent Component Analysis (ICA), Artificial Neural Networks (ANN), and Support Vector Machines (SVM).

The simplicity of multivariate statistical analysis approach is that there is no need for a fundamental model of the system and only data from normal operation needs to be used, which is generally available in some form for most machines. Among the approaches used in multivariate analysis are: two projection methods called principal component analysis PCA, projection to latent structure PLS [48, 49, 50]. Many applications of these two techniques have been successfully applied in other fields of process monitoring.

This paper outlines the use of the multivariate latent approach, to develop a framework for monitor heath status of automotive mechanical transmissions gear system under study. Models based on PCA and PLSDA are developed so that automotive mechanical transmissions gear can be monitored using the latent space of these models.

\section{System Configuration}

An automotive mechanical transmissions gear test rig is currently being developed for this ongoing research. The rig comprises $130 \mathrm{~mm}$ centre distance gearbox. Table1 provides the basic geometry specification for the gears. The system is driven by a $7.5 \mathrm{Kw}$ variable speed electric motor controlled by an inverter to provide a speed variation of $1750 \mathrm{rpm}$. The load is applied via a mechanical breaking mechanism.

Table 1. Gears basic geometry.

\begin{tabular}{|c|c|c|c|c|c|c|c|c|c|c|}
\hline \multirow{3}{*}{ Specifications } & \multicolumn{10}{|c|}{ Gear number } \\
\hline & \multicolumn{2}{|c|}{1} & \multicolumn{2}{|c|}{2} & \multicolumn{2}{|c|}{3} & \multicolumn{2}{|c|}{4} & \multicolumn{2}{|c|}{5} \\
\hline & $P$ & W & $\mathrm{P}$ & W & $\mathrm{P}$ & $\mathrm{W}$ & $\mathrm{P}$ & W & $\mathrm{P}$ & W \\
\hline Module (mm) & 9.5 & 9.5 & 9.5 & 9.5 & 8 & 8 & 8 & 8 & 8 & 8 \\
\hline Gear Type (H-S) & $\mathrm{S}$ & $\mathrm{S}$ & $\mathrm{H}$ & $\mathrm{H}$ & $\mathrm{H}$ & $\mathrm{H}$ & $\mathrm{H}$ & $\mathrm{H}$ & $\mathrm{H}$ & $\mathrm{H}$ \\
\hline Number of teeth & 21 & 40 & 19 & 35 & 30 & 33 & 38 & 25 & 43 & 20 \\
\hline $\begin{array}{c}\text { Face Width } \\
(\mathrm{mm})\end{array}$ & 25 & 25 & 25 & 25 & 25 & 25 & 25 & 25 & 30 & 30 \\
\hline Gear Ratio & \multicolumn{2}{|c|}{4.095} & \multicolumn{2}{|c|}{3.96} & \multicolumn{2}{|c|}{2.365} & \multicolumn{2}{|c|}{1.414} & \multicolumn{2}{|c|}{1} \\
\hline
\end{tabular}


The rig can generate a load torque on the test gears in the range of $0-200 \mathrm{Nm}$. The torque is measured using calibrated strain gauges installed on the shaft and the measured torque values are transmitted to the control program by telemetry in order to provide torque control of the loading mechanism on the mechanical transmissions. The test rig is shown in Figure 1. The testing system has been developed for this research work, and is capable of on-line monitoring, automatic measurement, and analysis. Also, any changes in the gears and bearing conditions due to degradation during the operation can be identified. The advantage of developing the system arises from its ability to enhance online analysis methods for vibration technique to provide robust information about the system's condition. Two temperatures were measured: gearbox oil temperature and bearing temperature using RTD temperature sensors $(10 \mathrm{mv} / \mathrm{C})$. The input shaft speed and motor current were also monitored as a precaution. The test rig operating conditions were monitored and it is flexibly changed according to the required test conditions using LabVIEW's virtual instrument scalable architecture features.

As shown in figure 1, the process is simply a multistage automotive gearbox. The gearbox is derived by a 3-phase electrical motor. The system is loaded through a mechanical braking system and controlled with an AC motor inverter. The system is equipped with five sensors, two accelerometers at two different positions (input and output of the gear system), temperature sensor (immersed in the gearbox oiling system), wireless strain gauge for torque measurements (on the output shaft) and a proximity sensor for speed measurement (at the gearbox input shaft).

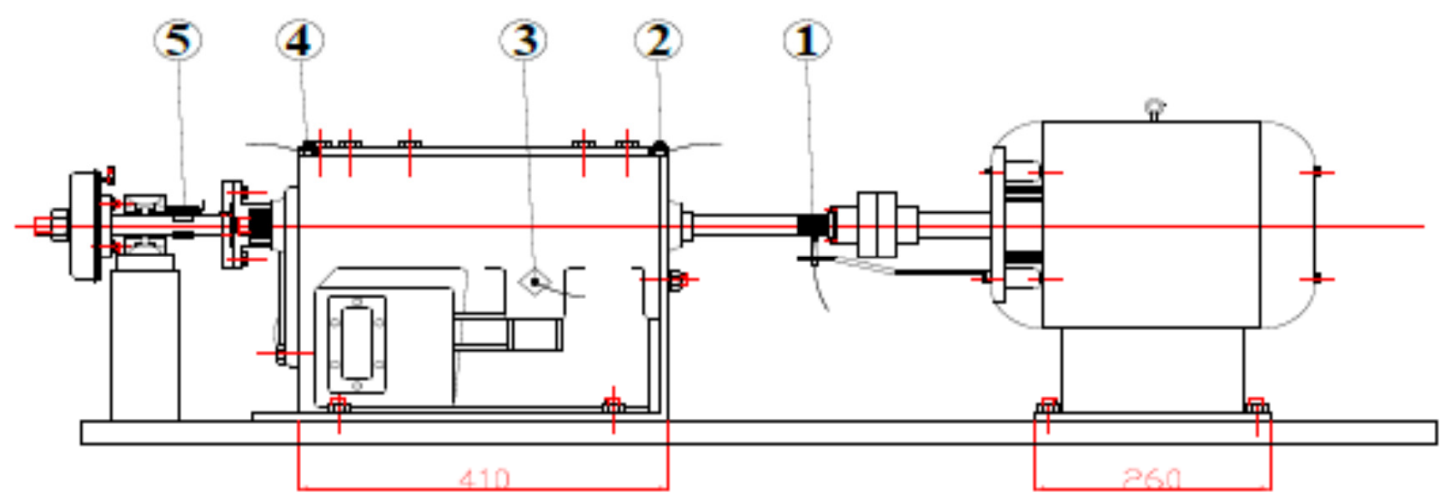

1. Speed sensor 2. Accelerometer 13 . Temperature sensor 4. Accelerometer 25 . Torque sensor

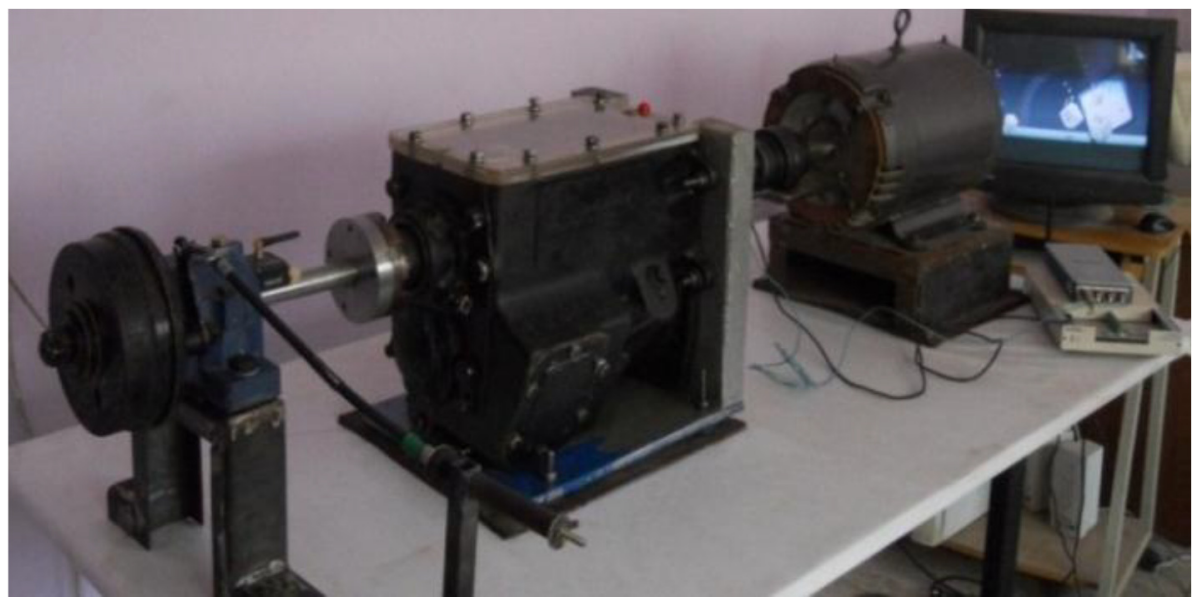

Fig. 1. Multistage gearbox System Scheme. 


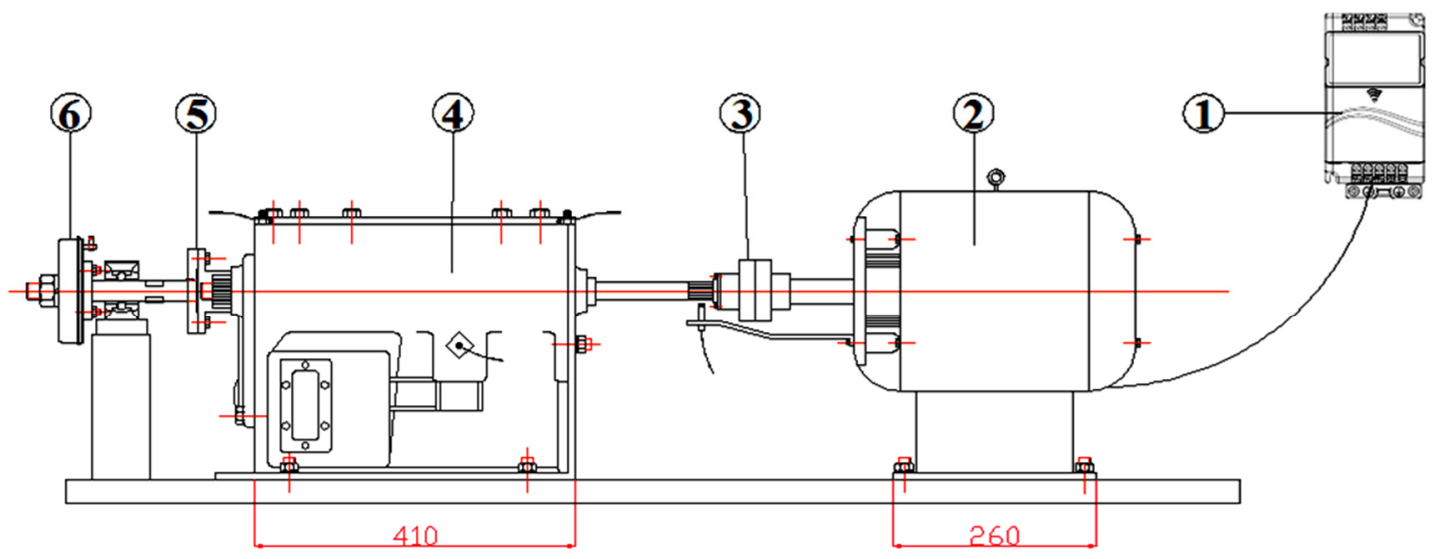

Fig. 2. 1. Inverter, 2. Electric motor, 3. Fixable coupling, 4. $130 \mathrm{~mm}$ center distance Gearbox, 5. Mechanical coupling, 6. Loading Mechanism.

The Vibration analysis system incorporated a 24-bit NI wireless DSA data acquisition card (NI 9234 with CDAQ-9191) to acquire the vibration signal, speed and temperature. The vibration signals were acquired using two DJB Piezotronic constant current source accelerometers (model no. Acc103-10mV/g) mounted adjacent to the tested gear bearings transversely to the gearbox casing, and a shaft speed sensor was used to acquire the shaft rotation reference. The sensors location diagram over the test rig is shown in Figure 2. The vibration signals are then acquired continuously and transmitted to the base unit using an IEEE $802.11 \mathrm{~b} / \mathrm{g}$ (Wi-Fi) wireless communication interface (frequency range $2.412-2.462 \mathrm{GHz}$ ). The system can send the data from a range up to $30 \mathrm{~m}$ for indoor measurements and $100 \mathrm{~m}$ for outdoor operation as long as the line of sight of the wireless signal is provided. The system can also provide Ethernet cabling measurements up to a distance of $100 \mathrm{~m}$. The test rig sensoractuation system layout is shown in Figure 3.

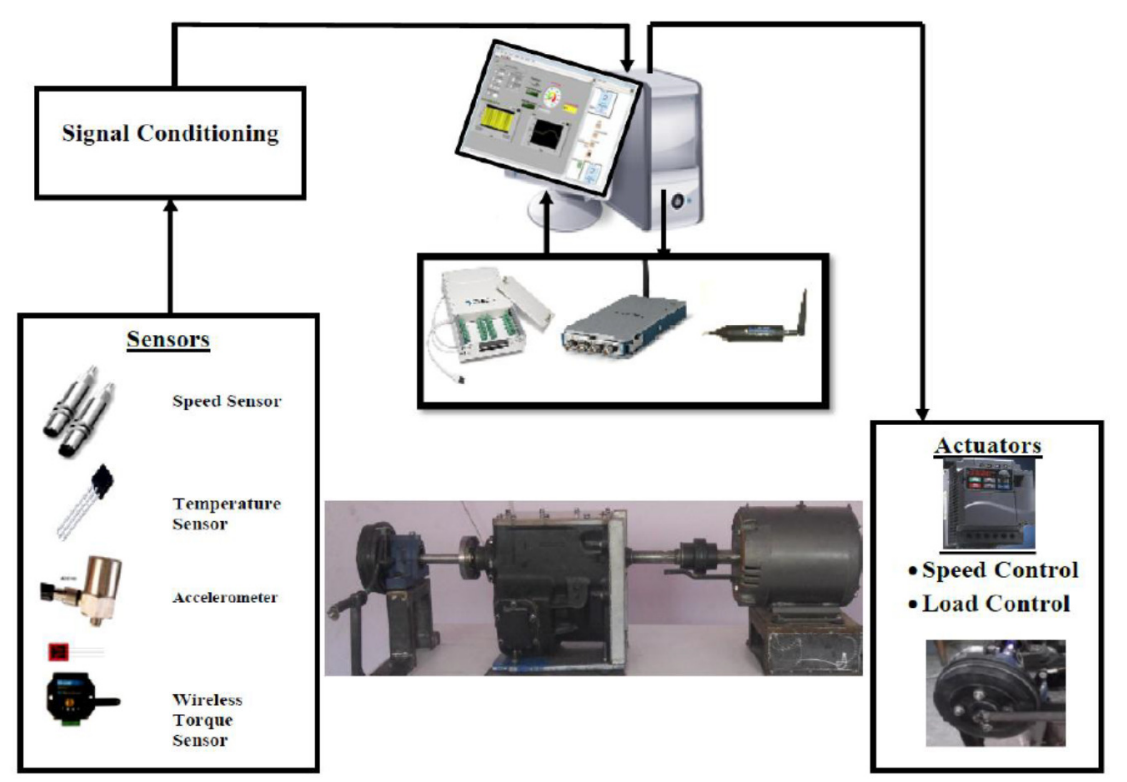

Fig. 3. The test rig sensors - actuation system layout. 


\section{MULTIVARIATE LATENT APPROCH (PCA)}

Principal component analysis decomposes the variance and covariance structure of a data matrix by defining linear combinations of the columns in the original matrix. Moreover, PCA extracts information from data sets by computing a smaller data set and other summary information that adequately captures most of the underlying features of the larger data set. The point that needs to be stressed is that the data can be reduced to a size which is more manageable but contains the features that are often of interest. PCA extracts a score matrix, $T$, and a loading matrix, $P$, from $X$. These matrices have the following dimensions $[10,13]$ :

$$
X: N \times K T: N \times A \quad P: K \times A
$$

The first column of $T$ and $P$ are called by their shorter forms, $t_{1}$ and $p_{1}$ respectively. The lower case letters indicate that these are vectors, upper case letters indicate matrices. Extracting only one principal component (that is, a single score vector and loading vector) gives:

$$
\mathrm{X}=\mathrm{t}_{1} p_{1}^{T}+\mathrm{E}_{1}
$$

Extracting a second principal component:

$$
\mathrm{X}=\mathrm{t}_{1} p_{1}^{T}+\mathrm{t}_{2} p_{2}^{T}+\mathrm{E}_{2}
$$

Principal components are extracted in same manner and then group these score and loading vectors to form matrices $\mathrm{T}$ and $\mathrm{P}$ :

$$
T=\left[t_{1} t_{2} \ldots t_{A}\right] \text { and } P=\left[p_{1} p_{2} \ldots p_{A}\right]
$$

The eigenvectors of the real symmetric matrix $X^{\top} X$ give us exactly the loading matrix $\mathrm{P}$. This is the loading matrix obtained by extracting all principal components. $\mathrm{P}$ is used to compute $\mathrm{T}$ :

$$
T P^{\top}=X \quad T P^{\top} P=X P \quad T=X P
$$

A more in-depth discussion, which also highlights some geometric concepts of PCA, can be found in [10]. The algorithm used to calculate the PCA is the NIPALS (Nonlinear Iterative Partial Least Squares) algorithm [10,13].

\section{RESULTS AND DISCUSSION}

This section discusses the results of the experimental study, showing the application of the PCA algorithm to real stored sensory data, for normal and anomalous operation periods.

Measurements were driven through five conditions as shown in figure 4. It shows Kurtosis and Crest factors of the input gearbox shaft through the different conditions. 


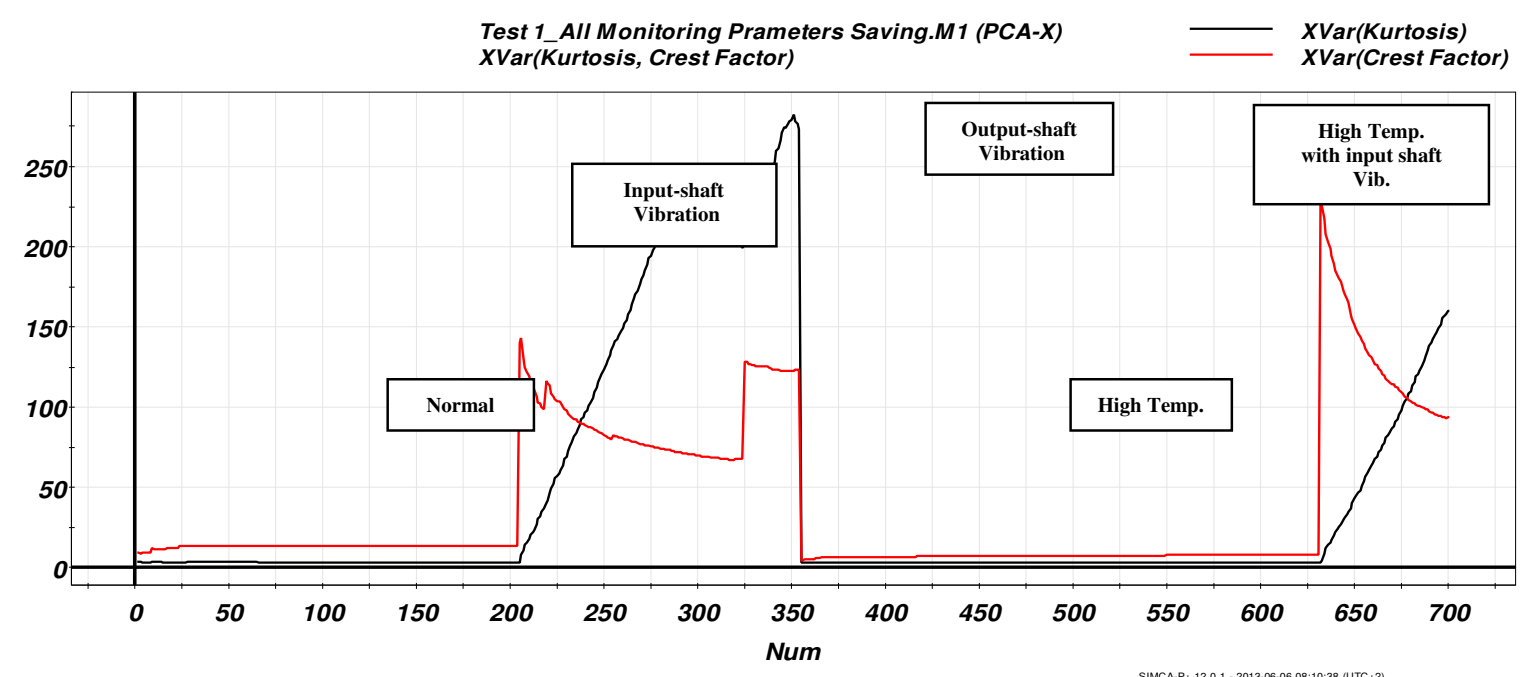

Fig. 4. Kurtosis, Crest factors and Temperature at the input gearbox shaft for 701 samples experiments.

First, the system was run under normal condition (observations 1-204), then external excitations were applied at two positions (input $\backslash$ output shaft: 205-320; 321-360). The system was then subjected to a high temperature (361-633) and finally, the system was run at high temperature with an external excitation at first position (input shaft: 634-701).

One way of evaluating and clustering database information, such as gearbox data, is the multivariate projection methods such as PCA. The projection aspect has an advantage when dealing with large amounts of collinear variables, noise, missing data and of course provides the reduction of dimensionality. Control charts based on these methods have been outlined by Kresta et al. [69]. Principal component analysis PCA finds latent directions that maximize the variance of the process. First, we must construct a complete system to collect useful information and then fuse them to detect different states of the system. To build such a system, there is a need for a system which can:

- Sense signals describing the multistage automotive gearbox system (Torque, speed, vibration...)

- Interpret incoming sensed information \& Facilitate decision making (normal, high temp. and excited system)

- Detect process shifts (General wear, new events)

- Control Charts to monitor important aspects.

A total of 27 features were used to generate the input matrix " $X$ ". All these features were obtained from time domain records (length 38000 cycles) of the torque, two positions vibration, temperature and speed. From each time domain record mean, minmax, Kurtosis, crest factor, RMS, peak, exponential, variance, sum and ARMA coefficients values were calculated. Adding up the mentioned features, the final Xmatrix is calculated with a total of 27 features. Model configuration for PCA is illustrated in the following sections. All the models were built using SIMCA-P code developed by Umetrics [11]. 
The multivariate PCA model is a linear model given in matrix form by: $X=T P^{\top}+E_{A}$ $[12,21]$. However, there exist non-linear PCA versions even by augmenting the original matrix with the non-linear factors or by building a non-linear relation between score factors [12]. To build the model using process variables, let $X$ include variables containing the information in the sensory data. Figure 5 illustrates how the score plot is built for a simple case 3-variables and 2-scores. After determining the direction of maximum variation by iterative steps and get the second orthogonal direction by the same way after subtracting the first component, we rotate the new plane determined by the new score variables $t_{1}$ and $t_{2}$ and then monitor the movement of the process variables in the reduced dimensional space during printing.

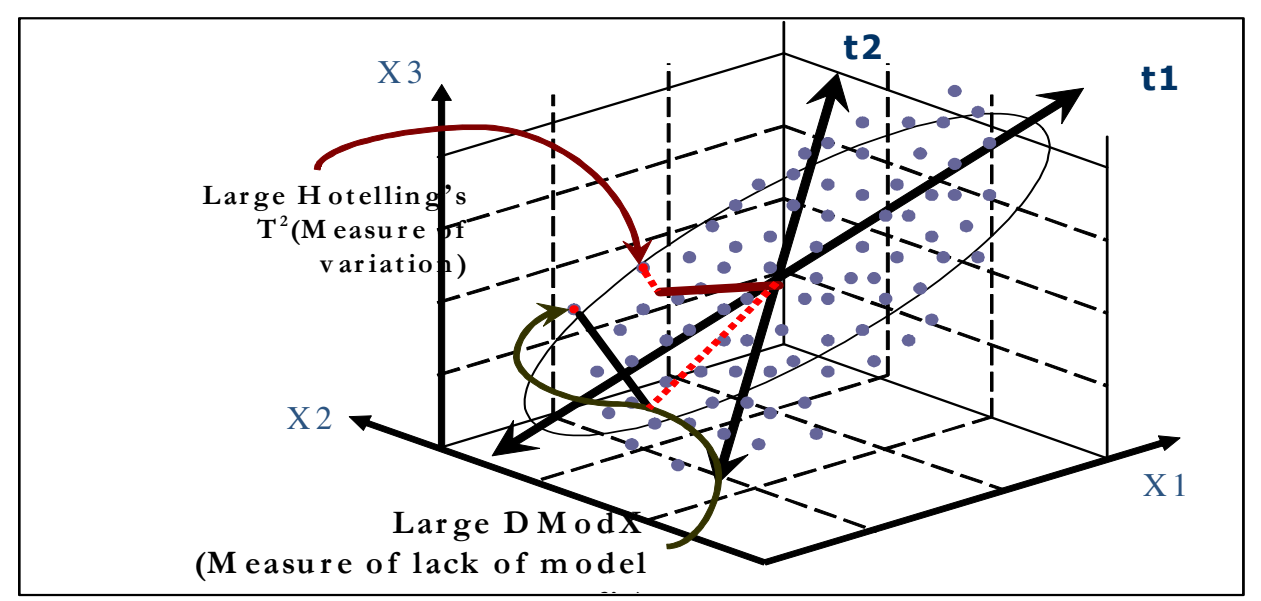

Fig. 5: illustrates how the score plot is built for a simple case 3-variables and 2-scores.

The PCA model is based on building classes or clusters using existing information inside the data (unsupervised learning). The model is established using a set of experimental runs called the training set that represents the normal operation of the gearbox system. Finally, regression is made on the matrix $X$ based on NIPALS algorithm. To explore the collected data a first model using PCA was built using all the dataset by cross-validation, now obtaining a two component model, with:R2X(cum): $0.73, \mathrm{Q} 2$ (cum) : 0.65. Figure 6 illustrates a scatter plot of the two score vectors ( $\mathrm{t} 1$ and t2) of the PCA model using a set of 701 observations. These observations represent five states of the multistage gearbox system: Normal, external excitations at two positions, high temperature and high temperature with an external excitation. The score plot provides a clear vision of the dispersion of the data, with the normal process data being discriminated against the abnormal data along the first two components. This clustering is indicated by triangle points and manually highlighted with dotted circles in the $t_{1} v s$. $t_{2}$ score plot in figure 6 . It can be seen from the figure that the PCA model succeeds in classifying the five states of the system.

More investigation carried out using control charts and contribution plots as shown in figure 7-11 to quickly assess which factors affect these different process shifts. Figure 7 shows the contribution plots for normal state. One can notice that both vibration excitations represented by Kurtosis, Crest factor, RMS, mean, peak and min-max values are low. Also, number of cycles and temperature are low at the beginning of the run. 


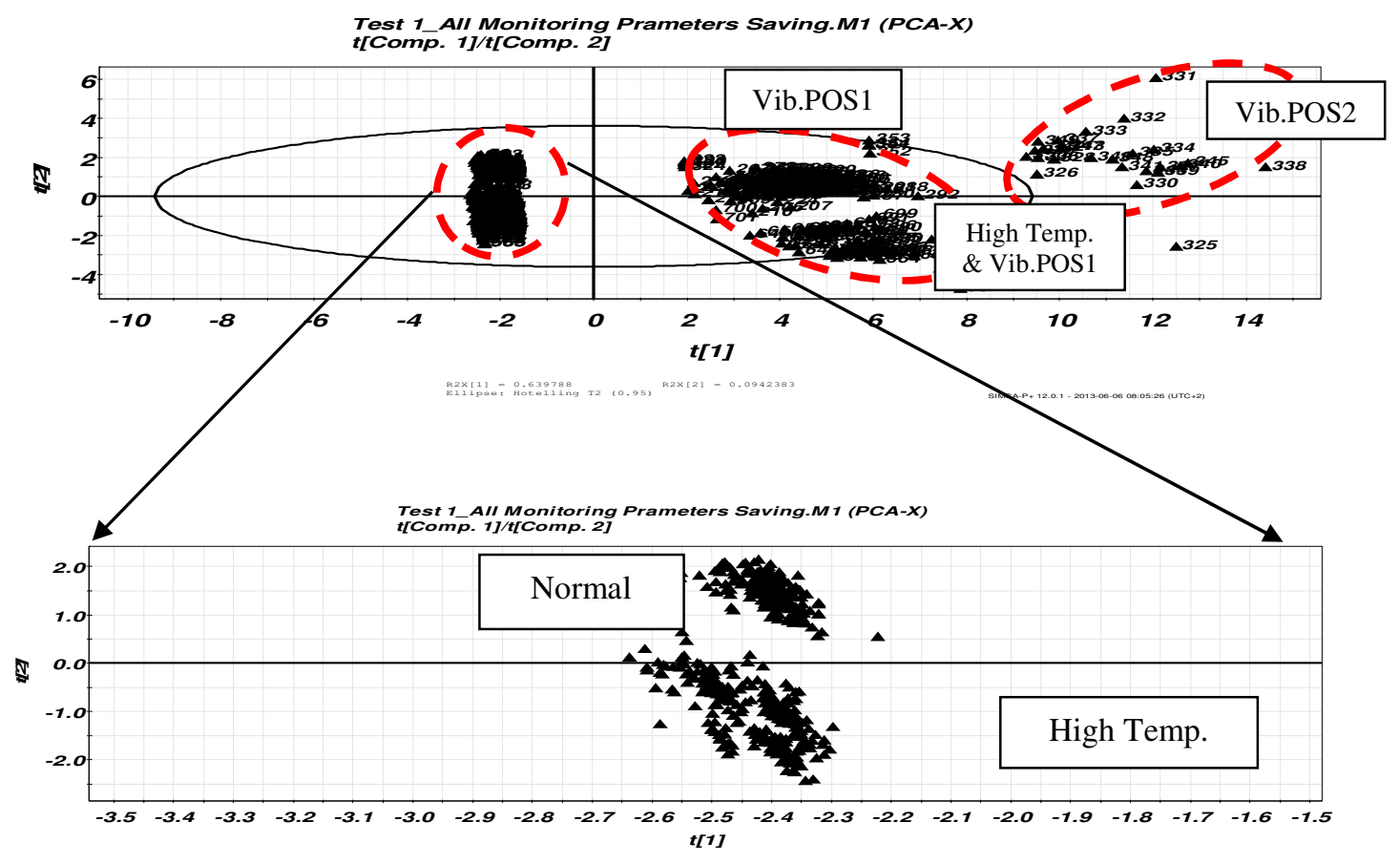

Fig. 6. illustrates a scatter plot of the two score vectors (t1 and t2) using a set of 701 observations.

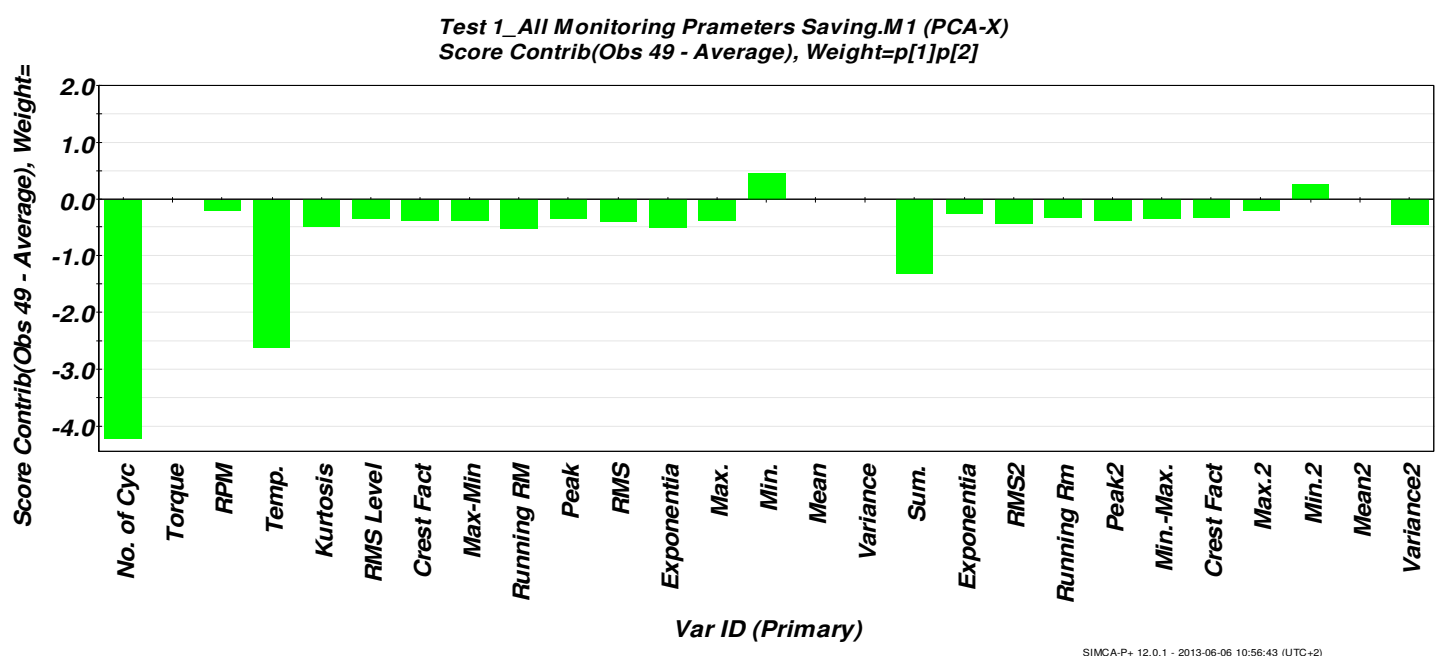

Fig. 7. Control chart for the contribution plots for normal state.

Figure 8 shows the contribution plots for high temperature state. One can notice that both temperature and number of cycles are high. Also, excitations represented by Kurtosis, Crest factor, RMS, mean, peak and min-max values are still low.

Figure 9 shows the contribution plots for external excitation at the input shaft state. One can notice that excitations represented by Kurtosis, Crest factor, RMS, mean, peak and min-max values at input shaft are higher than at output shaft measurements indicating the external excitation at the first position. 


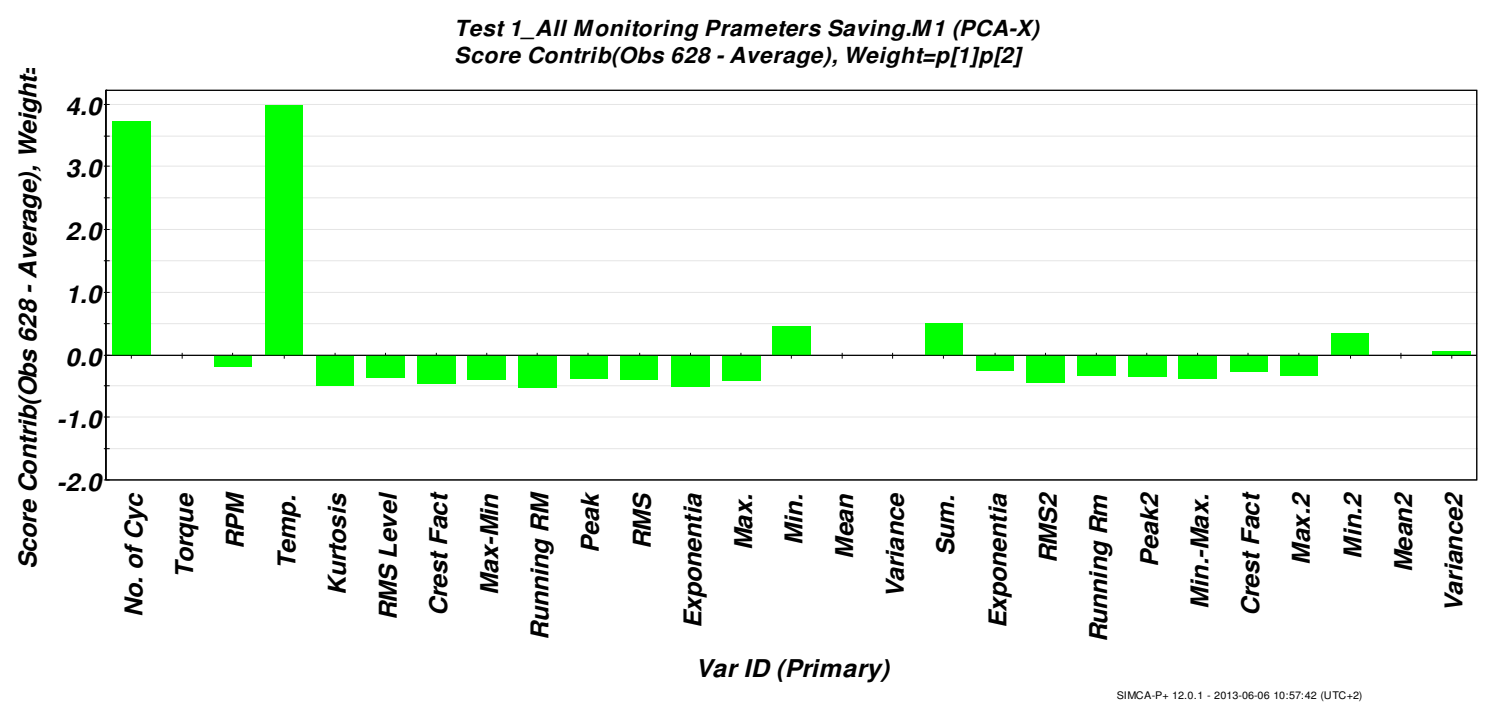

Fig. 8. Control chart for the contribution plots for high temperature.

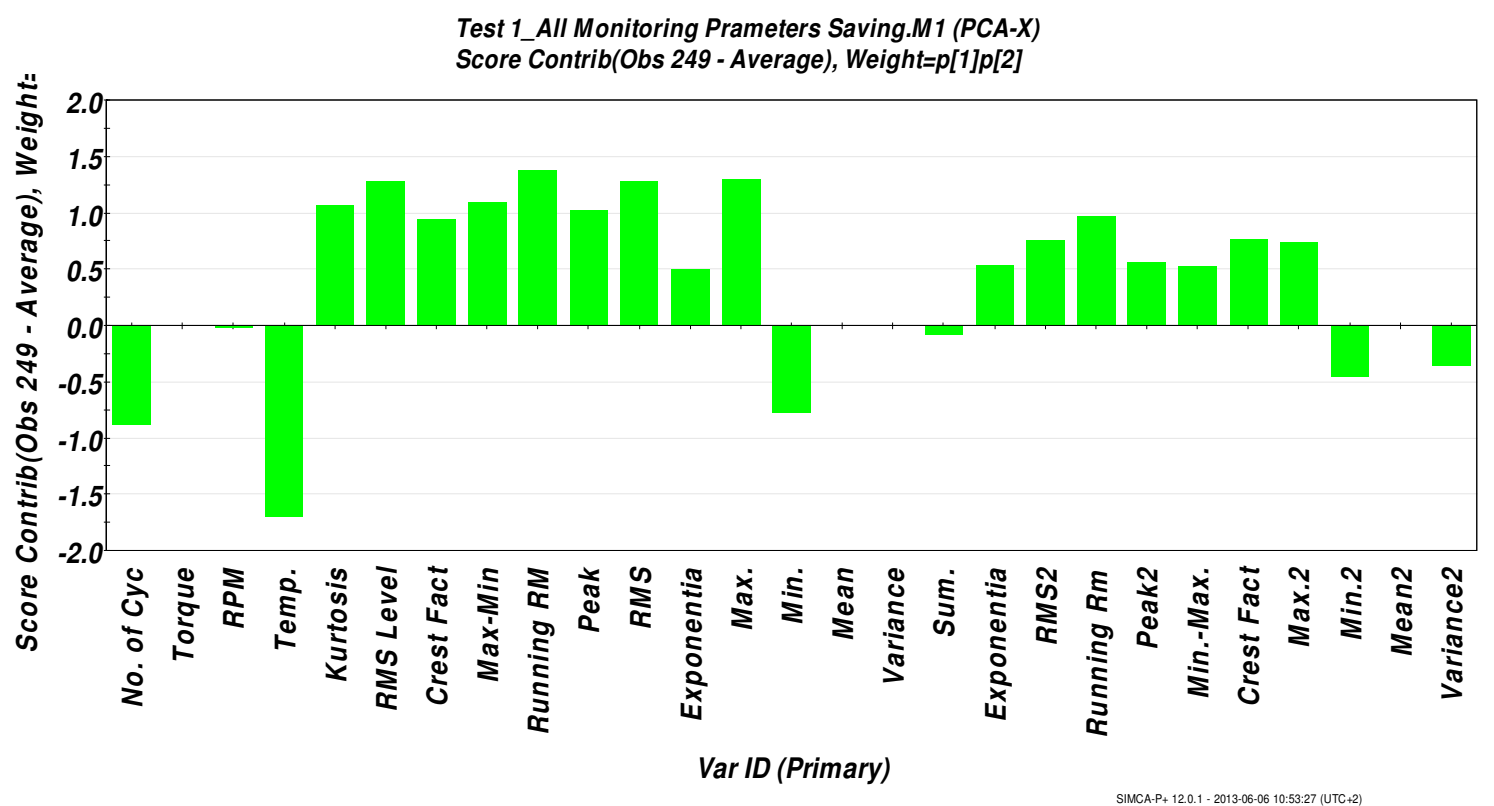

Fig. 9. Control chart for the contribution plots for external excitation at gearbox input position.

Figure 10 shows the contribution plots for external excitation at the output shaft state. One can notice that excitations represented by Kurtosis, Crest factor, RMS, mean, peak and min-max values at output shaft are higher than at input shaft measurements indicating the external excitation at the second position.

Figure 11 shows the contribution plots for external excitation at the input shaft state with high temperature state. One can notice that both excitations at position one and temperature are high indicating the vibration at the first position and high temperature. 


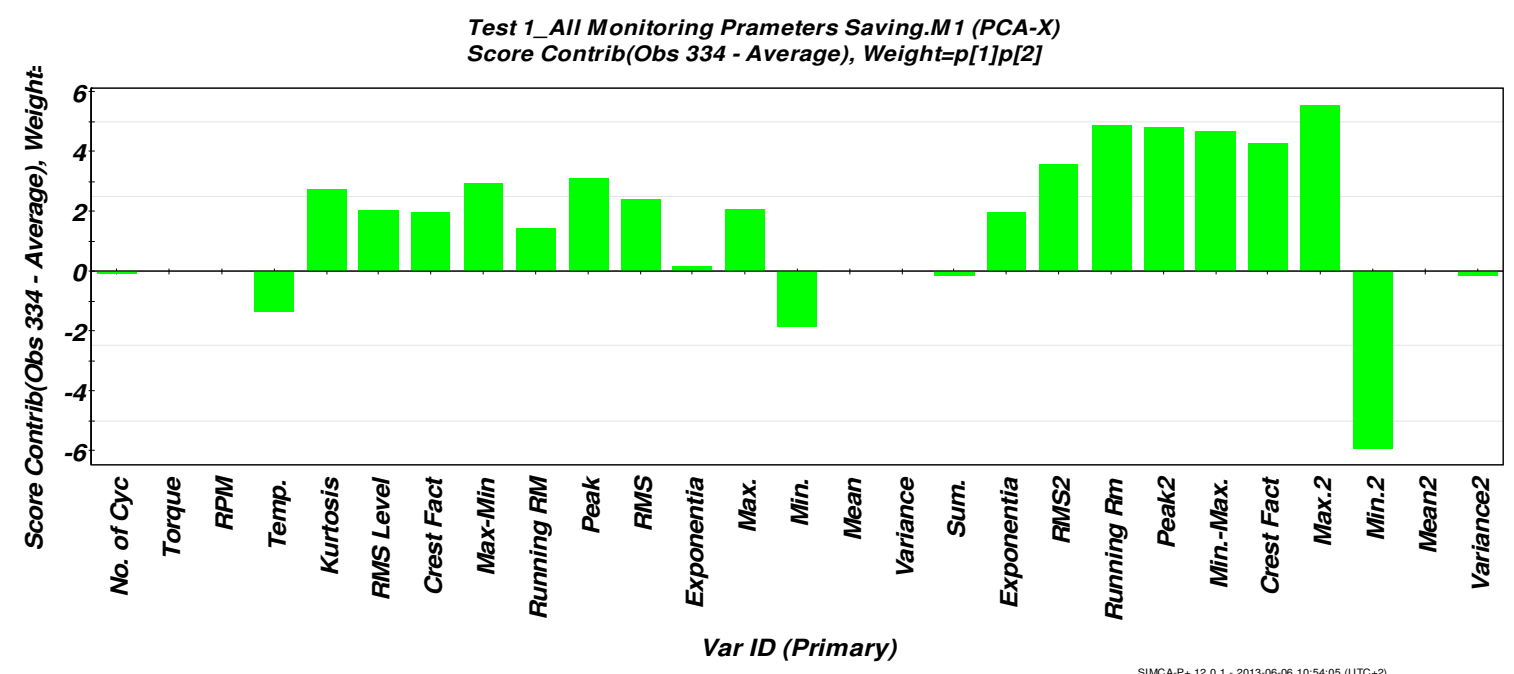

Fig. 10. Control chart for the contribution plots for external excitation at gearbox output position

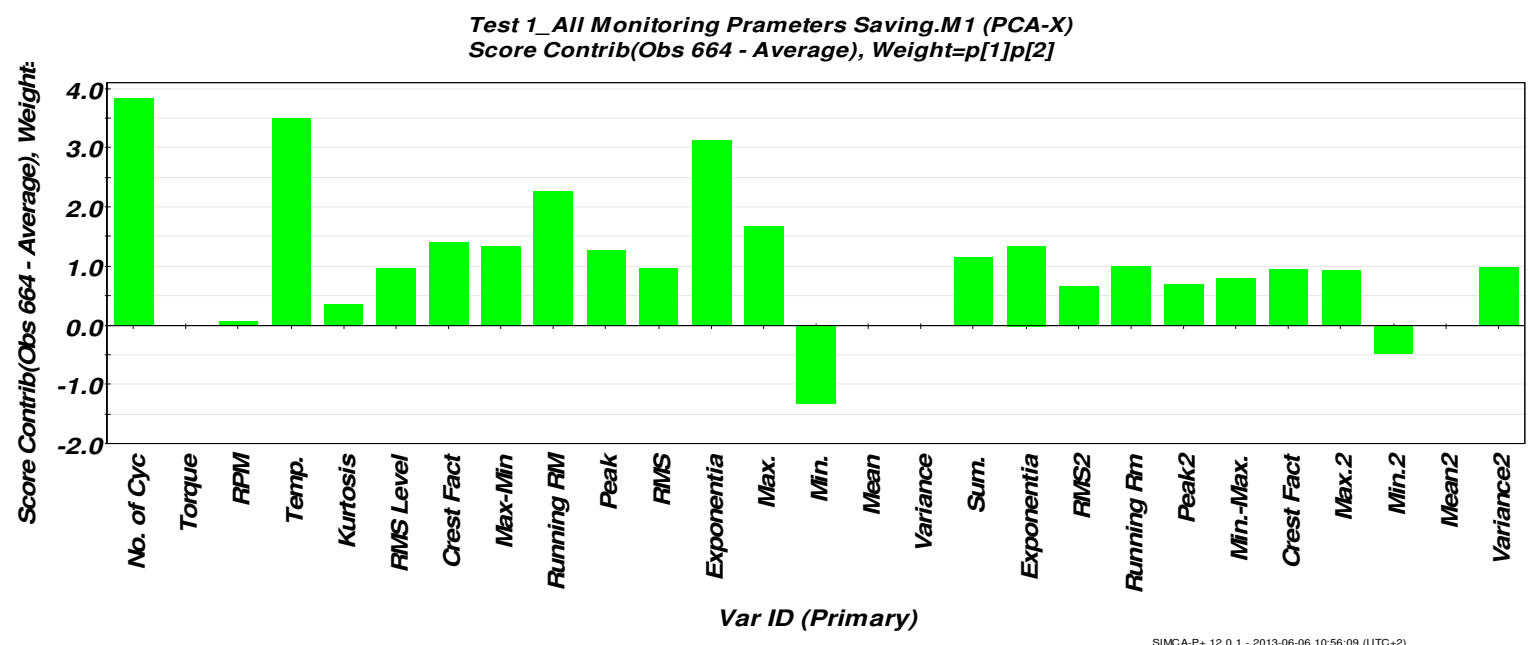

Fig. 11. Control chart for the contribution plots for external excitation at gearbox input position with high temperature

More analysis is made by examining the loading plot, which shows the relation between the different variables. Figure 12 shows the loading plot clarifying the relation between the 27 variables. In addition, the score and loading plots are superimposed; this means that variables lying in each quarter of the loading plot are contributing to the changes between the observations in the score plot. So, by investigating the loading plot (figure 12 ), one can detect directly which variables are responsible or more affecting a specified group of data in the score plot.

From these two figures, one can notice, how temperature and number of cycles parameters in the middle lower side of the loading plot contribute to the right lower swarm (high temp. state) of data in the score plot. In addition, vibration excitations 


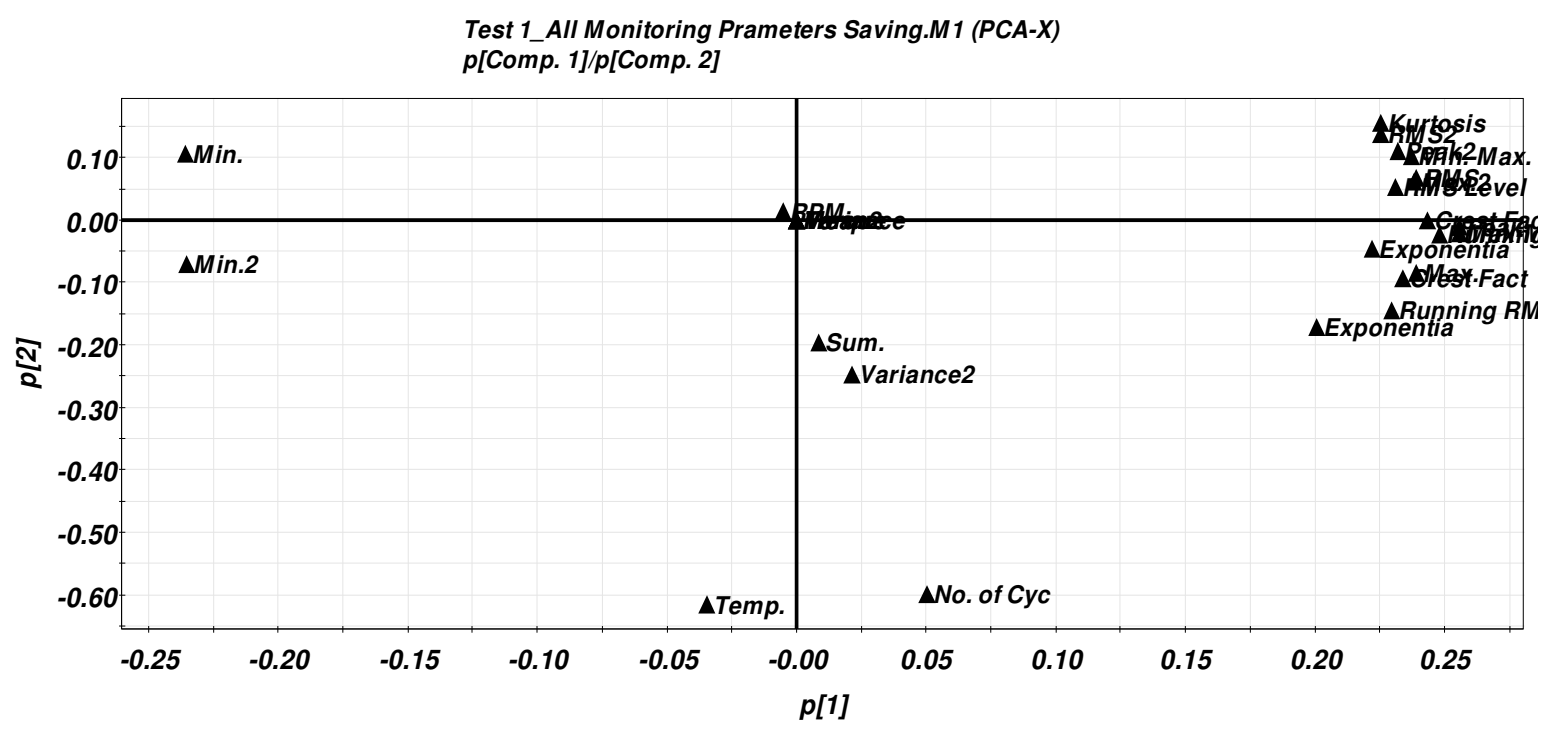

Fig. 12. PCA-X loading plot

represented by Kurtosis, Crest factor, RMS, mean, peak and min-max values for both positions input and output variables are contributing to the external excitation states as lying in the right side. Moreover, one can notice the gradual appearance of the faults, which takes a specific direction in the latent space. This illustrates the power of the proposed method for the early detection of the upcoming events.

A typical form in monitoring processes is to use a priori knowledge about the process by building the model based on normal data. Normal data are data gathered from a specific process under normal behavior including common cause variation. Then, the next step is to examine the model with different conditions (a validation data set). The final step is to detect new events or shifts from the original model using the contribution plots.

An attempt has been made to improve model capability by removing the variables of least important to the model as seen from the loading plot like the torque, rpm, peak, RMS, mean, variance etc.., now obtaining a two component model based on Kurtosis, two Crest factor, temperature and number of cycles using 181 normal observations only as training set. The model parameters are: R2X(cum): 0.85, Q2(cum) : 0.5. Figure 13- 14 shows the score and loading plots of the new model after removing least important factors. It can be noticed the good dispersion of the data in both directions $\mathrm{t}_{1}$ and t2.

In this application, out of the 701 observations (181 normal, 520 faulty states), a training set of 181 observations (normal) were chosen to develop the PCA regression model. The developed PCA model was then tested on a test set including some selected observations (290-310) external excitation at position one (input shaft).

It can be seen from figure 15 that the PCA model succeeds in classifying the new observations normal, and vibration at position one. 
Test 1_All Monitoring Prameters Saving.M8 (PCA-X)

t[Comp. 1]/t[Comp. 2]

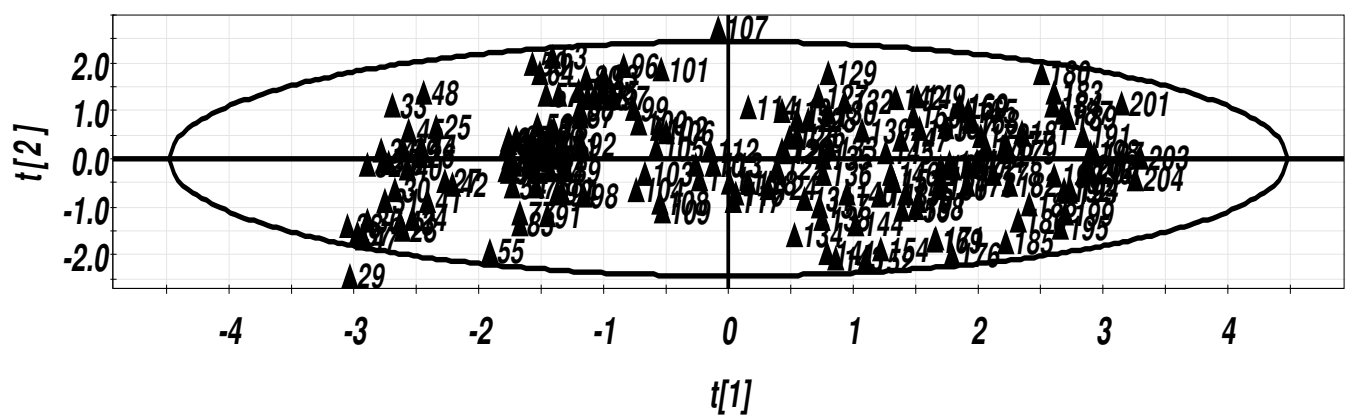

$\operatorname{R} 2 X[1]=0.655073 \quad R 2 X[2]=0.193984 \quad$ Ellipse: Hotelling $T 2(0.95)$

SIIMCA.P+ 12.01- 2013-06-07 01:23:23 (UTC+2)

Fig. 13. Score plot of the normal 181 observations.

Test 1_All Monitoring Prameters Saving.M8 (PCA-X)

p[Comp. 1]/p[Comp. 2]

Colored according to model terms

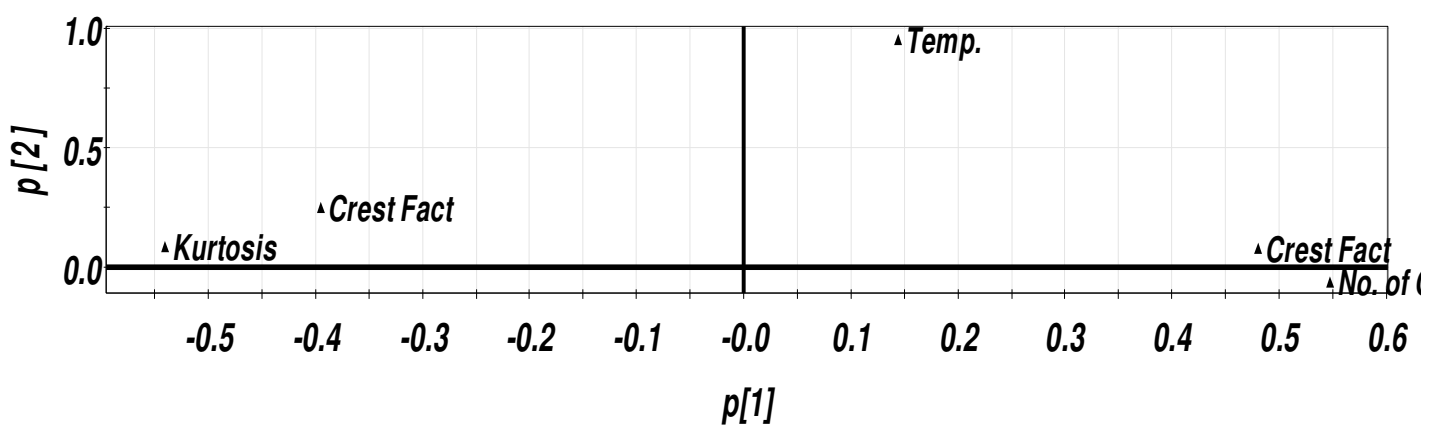

$\operatorname{R2X}[1]=0.655073 \operatorname{R} 2 X[2]=0.193984 \quad$ SIMCA.P+ 12.0.1- 2013-06.07 01:23:50 (UTC+2)

Fig. 14. Loading plot of the normal state.

Test 1_All Monitoring Prameters Saving.M8 (PCA-X), PS-Test 1_All Monitoring Prameters Saving tPS[Comp. 1]/tPS[Comp. 2]

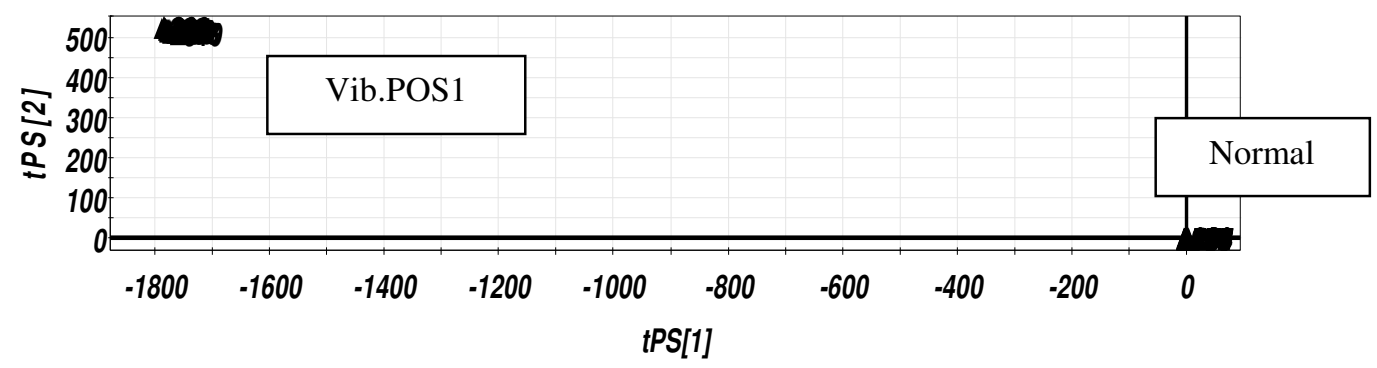

$R 2 X[1]=0.655073 \quad R 2 X[2]=0.193984 \quad$ E11ipse: Hotelling $\mathrm{T} 2(0.95)$

SIMCA.P+ 12.01 - 2013-06-07 01:56:47 (UTC+2)

Fig. 15. Score plot for prediction of new process events (high Vib. At position one). 
Figure 16 shows the contribution plots for high vibration at position one. One can notice that the Kurtosis and crest factors of the first accelerometer data are responsible for this shift, alarming on the occurrence of external excitation at position one.

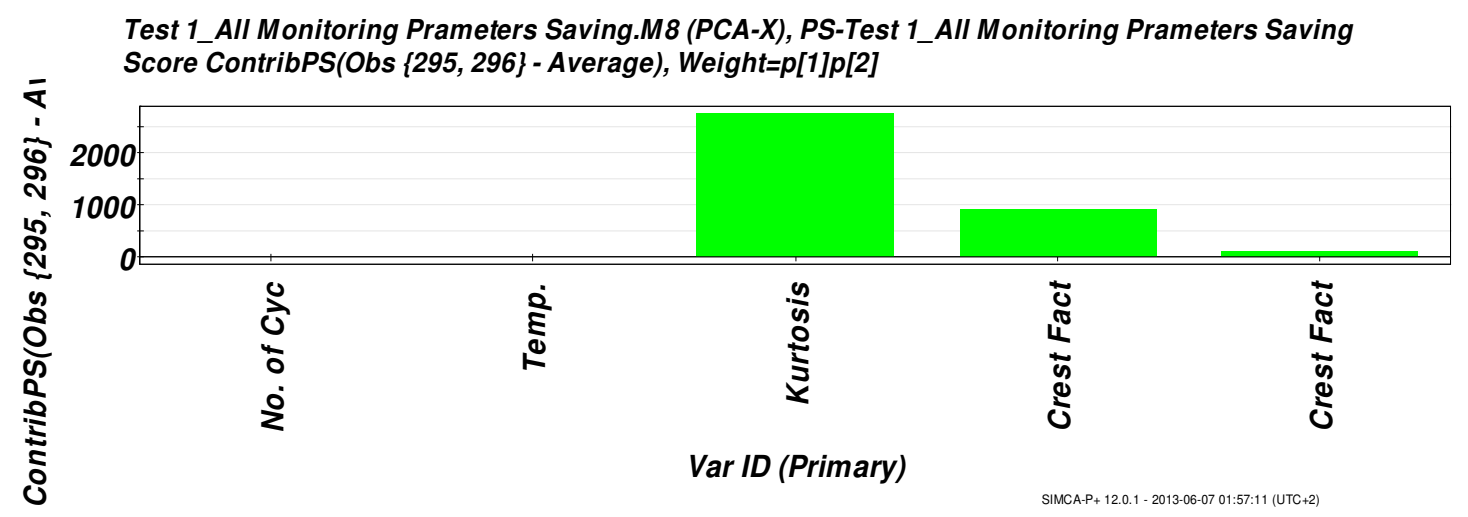

Fig. 16. Control chart for the test set high Vib at position one.

\section{CONCLUSION}

The study has presented the application of a statistical soft sensor PCA to monitor the progression of gear faults in spur and helical gears. Measurements were collected using a wireless vibration measuring system on an automotive gearbox. Sensory system consists of two accelerometers at two different positions (input and output of the gear system), temperature sensor (immersed in the gearbox oiling system), wireless strain gauge for torque measurements (on the output shaft) and a proximity sensor for speed measurement (at the gearbox input shaft). The online information about the transmission condition can provide a solution for PHM systems. The model was tested under different conditions including: normal condition, external excitations at two positions (input/output shaft), high temperature and high temperature with external excitation and was able to successfully differentiate between them.

\section{REFERENCES}

[1] Scheffer, C. and Girdhar, P. (2004) Machinery Vibration Analysis and Predictive Maintenance, Newnes Press; ISBN 0750662751.

[2] SMITH, J.D. (1983) Gears and Their Vibration: A Basic Approach to Understanding Gear Noise, New York: M. Dekker; London: Macmillan Press.

[3] ONSY, A., SHAW, B.A. \& JISHAN, Z. (2011) Monitoring the Progression of Micro-Pitting In Spur Geared Transmission Systems Using Online Health Monitoring Techniques. SAE International Journal of Aerospace. November 20114:1301-1315.

[4] ONSY, A., BICKER, R., SHAW, B.A., ROWLAND, C.W. \& KENT, T. (2008b) Monitoring Bending Fatigue Failure in Helical Gears Using Acoustic Emission, Vibration, and On-Line Oil Debris Analysis: A Comparative Study. Proceedings of the Fifth International Conference on Condition Monitoring \& Machinery Failure Prevention Technologies, UK, Edinburgh. 
[5] TAN, C.K., IRVING, P. \& MBA, D. (2005) Diagnostics and Prognostics with Acoustic Emission, Vibration and Spectrometric Oil Analysis For Spur Gears: A Comparative Study. Insight: Non-Destructive Testing and Condition Monitoring, 47, 478-480.

[6] AL-GHAMD, A.M. \& MBA, D. (2006) A Comparative Experimental Study on the Use of Acoustic Emission and Vibration Analysis for Bearing Defect Identification and Estimation of Defect Size. Mechanical Systems and Signal Processing, 20, 1537-1571.

[7] G. Dalpiaz, A. Rivola and R. Rubini, (2000) Gear Fault Monitoring: Comparison of Vibration Analysis Techniques, Department of Mechanical Design Engineering University of Bologna, Italy.

[8] C. James Li, J.D. Limmer, (2000) Model-based condition index for tracking gear wear and Fatigue damage, Wear 241_2000. 26-32, Department of Mechanical Engineering, Aeronautical Engineering and Mechanics, Rensselaer Polytechnic Institute, Troy, USA.

[9] Enayet B. Halim, Sirish L.Shah, Mingo j.Zuo and A. A. Shoukat Choudhury, (2004) Fault Detection of Gearbox from Vibration Signals using TimeFrequency Domain Averaging.

[10] Johan Wandell, (2006) Multistage Gearboxes: Vibration Based Quality Control, TRITA-AVE 2006:27 ISSN 1651-7660, Royal Institute of Technology School of Engineering Sciences Department of Aeronautical and Vehicle Engineering the Marcus Wallenberg Laboratory for Sound and Vibration Research.

[11] P.Gupta, S. B. Wadkar, (2008) Comparative Vibration and Noise Signature Analysis by Spectral, Cepstral and Wavelet Techniques, P.Gupta and S. B. Wadkar/ Advances in Vibration Engineering, 7(2) 2008 Department of Mechanical Engineering, College of Engineering, Bbartj Vidyapeeth Deemed University, India.

[12] Grzegorz Wojnar, Bogusław Lazara, Henryk Madej, (2008) Diagnostics of Power Transmissions System with Tooth Gear, Silesian University of Technology, Faculty of Transport, Department of Automotive Vehicle Construction, Poland.

[13] Matej Gasperin, ani Juricic, Pavle Boskoski, Joz ef Vizintin, (2011) Modelbased Prognostics of Gear Health using stochastic dynamical models, Mechanical Systems and Signal Processing 25(2011) 537-548, Department of Systems and Control, Slovenia.

[14] ONSY, A., BICKER, R. \& SHAW, B.A. (2010) A Novel Intelligent Health Monitoring System for Gear Fatigue Failure Prediction. 23rd International Congress on Condition Monitoring and Diagnostic Engineering Management; COMADEM 2010, Japan, Nara, ISBN 978-4-88325-419-4.

[15] ONSY, A., BICKER, R. \& SHAW, B.A. (2010) Intelligent Diagnostic Health Management of Power Transmission Systems: An Experimental Validation, International Journalof COMADEM 2010, 13(2), 46-58.

[16] ONSY, A., BICKER, R., SHAW, B.A., ROWLAND, C.W. \& KENT, T. (2009) Intelligent Health Monitoring Of Power Transmission Systems: An Experimental Validation. Proceedings of the 2009 Conference of the Society for Machinery Failure Prevention Technology, USA, Dayton, Ohio, 499-518.

[17] ONSY, A., BICKER, R., SHAW, B.A., ROWLAND, C.W. \& KENT, T. (2008a) Monitoring the Progression of Micro-Pitting in Helical Gears: Towards an Intelligent Health Monitoring System. Paper presented at the AEWG-51 \& International Symposium on AE, USA, Memphis, Tennessee. 
[18] Paula J. Dempsey, Abdollah A. Afjeh, (2002) Integrating Oil Debris and Vibration Gear Damage Detection Technologies Using Fuzzy Logic, NASA/TM-2002- 211126, National Aeronautics and Space Administration Glenn Research Center, USA.

[19] Abhinav Saxena, Ashraf Saad, PhD, (2005) Evolving an Artificial Neural Network Classifier For Condition Monitoring of Rotating Mechanical Systems, Journal of Applied Soft Computing Elsevier Publishers, ISSN: 1568-4946, School of Electrical and Computer Engineering, Georgia Institute of Technology, Savannah, a 31407, USA.

[20] T. H Loutas, J. Kalaitzoglou, G. Sotiriades, V. Kostopoulos, (2005) the Combined Use of Vibration, Acoustic Emission and Oil Debris Sensor Monitored Data Coming from Rotating Machinery for the Development of a Robust Health Monitoring System, Department of Mechanical Engineering and Aeronautics, University of Patras, Patras.

[21] M.H. Sadeghi, J. Raflee, F. Arvani, and A. Harifi, (2006) A Fault Detection and Identification System for Gearboxes using Neural Networks, Center of Excellence for Mechatronics, University of Tabriz, Tabriz, Iran.

[22] J. Rafiee, F. Arvani, A. Harifi, M.H. Sadeghi, (2007) intelligent condition monitoring of a Gearbox using artificial neural network, Mechanical Systems and Signal Processing 21 (2007) 1746-1754, Department of Mechanical Engineering, University of Tabriz,Tabriz, Iran.

[23] S.J. Loutridis, (2008) Gear failure prediction using multiscale local statistics, Engineering Structures 30 (2008) 1214-1223, Technological Educational Institute of Larissa, School of Technological Applications, Department of Electrical Engineering, Sensors an Instrumentation Laboratory, GR 41-110 Larissa, Greece.

[24] T.H. Loutas, G. Sotiriades, I. Kalaitzoglou, V. Kostopoulos, (2009) Condition monitoring of $A$ Single Stage gearbox with artificially induced gear cracks utilizing on-line vibration and Acoustic Emission measurements, Applied Acoustics 70(2009)1148-1159, Department of Mechanical Engineering and Aeronautics, University of Patras, Patras GR-26500, Greece.

[25] N. Saravanan, S. Cholairajan, K.I. Ramachandran, (2009) Vibration-based fault diagnosis of Spur Bevel gear box using fuzzy technique, Expert Systems with Applications 36 (2009) 3119-3135, Department of Mechanical Engineering, Amrita Vishwa Vidyapeetham, Coimbatore, Tamil Nadu 641105, India.

[26] J. Rafiee, P.W.Tse, (2009) Use of autocorrelation of wavelet coefficients for fault diagnosis, Mechanical Systems and Signal Processing 23 (2009) 15541572, Department of Mechanical, Aerospace and Nuclear Engineering, Jonsson Engineering Center, Troy, USA.

[27] J. Rafiee , M.A. Rafiee, N. Prause , P.W. Tse, (2010) Application of Daubechies 44 in Machine Fault Diagnostics, Dept. of Mechanical, Aerospace \& Nuclear Engineering, Rensselaer Polytechnic Institute, NY, USA.

[28] Piotr Czech, .Boguslaw Lazar, Henryk Madej, Grzegorz Wojnar, (2010) Classification Of Tooth Gear Wheel Faults of Gearbox Working In the Circulating Power Test Rig By Multilayer Perceptron and Continuous Wavelet Transform, ACTA Technica Corviniensis - Bulletin of Engineering ISSN: 20673809, Faculty of Transport, Silesian University of Technology, Gliwice, POLAND. 
[29] Hongyu Yang, Joseph Mathew and Lin Ma, (2003) Vibration Feature Extraction Techniques For Fault Diagnosis of Rotating Machinery-A Literature Survey, Asia- Pacific Vibration Conference, 12-14 November 2003, Gold Coast, Australia, School of Mechanical Manufacturing and Medical Engineering, Australia.

[30] ONSY, A., BICKER, R. \& SHAW, B.A. (2013) Predictive Health Monitoring of Gear Surface Fatigue Failure Using Model-based Parametric Method Algorithms; An Experimental Validation. SAE International Journal of Aerospace. September 2013 Issue.

[31] ABELAZEZ, W.,ONSY, A.\& SHERIF, I. (2013) (in press) Health Monitoring of Electro-Pneumatic Controlled Systems using Multivariate Latent Methods: An Experimental Validation, SAE International Journal of Materials and Manufacturing 2013 Issue.

[32] ONSY, A., BICKER, R., SHAW, B. A. \& FOUAD, M. (2012) Application of Image Registration Techniques in Monitoring the Progression of Surface Fatigue Failures in Geared Transmission Systems.The AeroConf 2012 IEEE Aerospace Conference, USA, Big Sky.

[33] JAIN, L. C. \& SILVA, C. W. (1999) Intelligent Adaptive Control, Industrial Applications.

[34] SAMUEL, P.D. \& PINES, D. J. (2005) A Review of Vibration-Based Techniques for Helicopter Transmission Diagnostics. Journal of Sound and Vibration, 282, 475- 508.

[35] BRAUN, S. (1986) Mechanical Signature Analysis - Theory and applications. London: Academic Press Inc.

[36] Fenton, W.G., McGinnity, T.M., \& Maguire, L.P. (2001) Fault Diagnosis Of Electronic Systems Using Intelligent Techniques: A Review. IEEE Transactions on Systems, Man and Cybernetics Part C: Applications and Reviews, 31, 269281.

[37] Jardine, A.K.S., Lin, B., \& Banjevic, D. (2006) A Review On Machinery Diagnostics And Prognostics Implementing Condition-Based Maintenance, Mechanical Systems and Signal Processing, 20, 1483-1510.

[38] Iverson, D.L., Martin, R., Schwabacher, M., Spirkovska, L., Taylor, W., Mackey, R., and J. Castle, J.P. "General Purpose Data-Driven System Monitoring for Space Operations," AIAA Infotech @ Aerospace Conference, Seattle, WA, October 2010.

[39] David L. Iverson "Data Mining Applications for Space Mission Operations System Health Monitoring," NASA Ames Research Center, Moffett Field, California, 94035 Space Operations Conference, 2008.

[40] Takehisa Yairi, Minoru Inui, Akihiro Yoshiki, Yoshinobu Kawahara, Noboru Takata, "Spacecraft Telemetry Data Monitoring by Dimensionality Reduction Techniques," SICE Annual Conference, 2010.

[41] J.F.MacGregor, H.Yu, S. Munoz and J.Cerrillo, "Data-based latent variable methods for process analysis, monitoring and control," Journal of Computers and Chemical Engineering 29, 1217-1223, 2005.

[42] P. P. Nomikos and J. MacGregor, "Monitoring batch processes using multiway principal component analysis," AIChE J., Vol.40, 1361, 1994.

[43] L.Eriksson, E.Johansson, N.K. Wold and S.Wold, "Multi- and Megavariate data analysis, principles and applications;" Umetrics AB, Sweden, 2006. 
[44] Iverson, D. L., "Inductive System Health Monitoring," Proceedings of the 2004 International Conference on Artificial Intelligence (IC-AI04), CSREA, La Vegas, Nevada, June 2004.

[45] John MacGregora; Ali Cinarc; "Monitoring, fault diagnosis, fault-tolerant control and optimization: Data driven methods," Journal of Computers and Chemical Engineering 47, June 2012.

[46] Jian Peng, Linjun Fan,Weidong Xiao, and Jun Tang "Anomaly Monitoring Method for Key Components of Satellite,"Scientific World Journal Volume 2014, Article ID 104052, January 2014.

[47] J.E.Jackson, "A User's Guide to Principal Components," Wiley, New York, 1991.

[48] S.Wold, M.Sjostrom and L.Eriksson, "PLS-regression: a basic tool of chemometrics," Chemometric and intelligent laboratory systems, 58:109-130, 2001.

[49] I.T.Jolliffe, "Principle component analysis", springer virlag, New York, 1986.

[50] ] L. Simar and W.Hardle, "Applied Multivariate Statistical Analysis," Tech method and data technologies, Springer Verlag, Berlin and Louvain-la-Neuve, 2003. 